\title{
Notas sobre el nacionalismo de Moulines
}

\author{
LUIS VILLORO \\ Instituto de Investigaciones Filosóficas \\ Universidad Nacional Autónoma de México
}

\begin{abstract}
RESUMEN: Este texto versa sobre un artículo de Ulises Moulines, publicado en el número 46 de Diánoia. El autor está de acuerdo con Moulines en sostener que "nación" es un concepto teórico, pero presenta varios comentarios críticos que pretenden precisar ese concepto: tiene que basarse en datos objetivamente comprobables y, sobre todo, proponer definiciones adecuadas de "nación" y "nacionalismo" que, a la vez, sean aplicables al derecho y eviten equívocos. Cualquier propuesta teórica sobre esos conceptos supone una crítica a la idea moderna del Estado-nación homogéneo y el proyecto de un Estado plural.
\end{abstract}

PALABRAS CLAVE: nación, nacionalismo, etnia, Estado-nación, conceptos teóricos

En el número 46 de Diánoia, Ulises Moulines publicó un artículo intitulado "Manifiesto nacionalista (o hasta separatista, si me apuran)". Se trata de una contribución importante al esclarecimiento de los conceptos de "nación" y "etnia". Sostiene que esas nociones tienen el estatuto de "conceptos teóricos". Estoy de acuerdo con su tesis general; pero haré algunas breves observaciones para intentar precisarla.

1. Si "nación" es un concepto teórico, tenemos que determinar: 1) los fenómenos observables que el concepto trata de comprender; 2) la relación de ese concepto con otros, en el seno de una teoría.

Respecto del primer punto, los fenómenos por explicar tienen que ser observables y susceptibles de comprobación intersubjetiva. Siguiendo cierto consenso entre los antropólogos, yo propuse los siguientes: pese a la diversidad de formas y niveles de cultura en una sociedad, si hablamos de un "pueblo", de una "nación" o de una "etnia", tenemos que suponer ciertos rasgos culturales comunes a la mayoría de los grupos sociales que lo integran; éstos deben ser comprobables objetivamente, por ejemplo: uso de una lengua, formas de vida consensuadas, tradiciones comunes, instituciones culturales, sociales e incluso políticas. Otras dos notas que yo señalaba, pertenencia y proyecto histórico compartido, tienen una expresión subjetiva: atañen a una decisión voluntaria y a una identificación personal; pero también pueden expresarse en datos objetivos: relaciones familiares, residencia, participación en la vida social y política, cooperación en tareas comunes. La última nota también es de carácter objetivo: la relación con 
un espacio territorial. Éste puede ser el espacio que realmente ocupa el pueblo o un territorio, de referencia simbólica, del que hubiera sido expulsado. Todos los datos con los que pretendía caracterizar un pueblo tienen límites imprecisos (como la mayoría de los datos sociales), pero son comprobables empíricamente, requisito indispensable para proponer un concepto teórico que intente comprenderlos y les preste unidad.

Moulines rechaza esa propuesta. Sin embargo, no tiene más remedio que aducir los mismos datos de la definición que critica, aunque, en mi opinión, de manera incompleta. Por un lado, admite que "las manifestaciones fenoménicas de las etnias son de carácter cultural"; señala que son entidades "genidénticas", esto es, que "preservan su identidad". Pero, en lugar de aducir condiciones comprobables, como instituciones sociales, relaciones de pertenencia o referencia a un territorio, menciona rasgos psicológicos subjetivos, como "amor a la patria" o "voluntad política". Esos rasgos son, sin duda, de importancia, pero no pueden reemplazar datos observables. Me temo que su propuesta de "nación" como concepto teórico lo obligaría a precisar la clase de fenómenos a que ese concepto se refiere. Si lo hace, creo que no podría evitar acudir a las descripciones de los antropólogos, que parece rechazar.

2. Toquemos ahora el segundo punto. Un concepto teórico debe formar parte de un sistema de conceptos. La teoría debe definir los conceptos y establecer una relación, lo más clara posible, entre ellos. La propuesta de Moulines y la mía difieren. Ambos distinguimos entre los conceptos de "nación" y de "Estado"; pero Moulines trata "nación" como una especie del concepto más general de "etnia" y yo prefiero tratar "etnia" y "nación" como especies de otro concepto más general: "pueblo". En cuanto se trate de una quaestio de nomine, carece de importancia. La elección entre una u otra nomenclatura sólo tiene sentido si atendemos a una conveniencia práctica. Por mi parte encuentro una, que me determinó a preferir la terminología propuesta. A diferencia de los conceptos en ciencias naturales, los que se refieren a realidades sociales tienen una doble dimensión: describen hechos y señalan normas. "Nación", por ejemplo, no es un término neutro; se refiere a un conjunto de relaciones humanas que incluyen actitudes hacia valores, los cuales dan lugar a enunciados normativos sobre cómo debemos habérnosla con esa entidad social. La realidad intersubjetiva "nación" o "pueblo" se refiere, por lo tanto, a relaciones compartidas que podemos describir, pero también a una estructura normativa, jurídica y moral, en la que ocupa un lugar esa realidad. Si he empleado el concepto de "pueblo", es porque he intentado responder a esa doble dimensión. "Pueblo", aunque término vago y ambiguo — como señala Moulines—, tiene un lugar en el Derecho 
Internacional (o "Interestatal") vigente, en la figura del "derecho de los pueblos", consagrada en múltiples convenios internacionales. Los "pueblos" se aceptan como "sujetos de autodeterminación", al igual que los Estados nacionales. Se trataría, pues, de definir "pueblo" adecuadamente para evitar su ambigüedad con otros usos y poder reivindicar su derecho de autodeterminación, evitando así la restricción de ese derecho a los Estados. En cambio, el término "nación" se confunde generalmente, en el lenguaje jurídico actual, con "Estado nacional", algo que tanto Moulines como yo queremos evitar. "Etnia", por otra parte, no es un término usual en el Derecho Internacional; cuando mucho se utiliza en instrumentos que consideran los derechos de "minorías". Por esa razón práctica, creo que es mejor utilizar "pueblo" como sujeto de derecho, con tal de definirlo con precisión, y no "nación".

3. La definición de Moulines de "nación" como "etnia con voluntad política" coincide con mi definición de "nacionalidad". Sin embargo, habría que precisar. Hay dos especies de "etnias". Unas comparten un proyecto común, tienen instituciones propias, un sentido de comunidad y se refieren a un territorio propio; éstas son, sin duda, equivalentes a "naciones" o "nacionalidades" (ejemplos: catalanes en España, inuits en Canadá, huicholes en México). Pero hay otras etnias que no tienen esas características, se encuentran desperdigadas en un territorio, mezcladas con otras etnias, y carecen de un proyecto comunitario; éstas no son equivalentes a "naciones", o a "pueblos" en mi terminología (ejemplos: afroamericanos en Estados Unidos, chinos en Indonesia, otomíes en México). Los primeros tendrían un "derecho de autodeterminación"; los segundos caerían bajo la acepción de "minorías". Esta distinción es importante en derecho.

4. La nación como concepto teórico comprende fenómenos observables que no se reducen a la "voluntad política". Creo que esto lo admitiría sin dificultad Moulines, pero convendría entonces precisar su definición. Para aplicar a una comunidad humana el término de "nación", con los derechos que implica, tendría que comprobar que esa comunidad posee una continuidad referida a un territorio (que puede ser el lugar que ocupa o una referencia histórica), mantiene instituciones culturales, sociales y, en ocasiones, políticas propias. El concepto de "etnia", en cambio, tal como lo utilizan los etnólogos, puede referirse a grupos sociales que no tienen esas características. Luego, "etnia con voluntad política" no basta para definir "nación".

5. "Nacionalismo" ha cobrado en nuestros días un sentido peyorativo; Moulines cambia su sentido usual; para ello lo desliga de toda actitud y política hegemónica. Por supuesto que, así restringido, ese sentido de "nacionalis- 
mo" sería plenamente aceptable. El problema es evitar la ambigüedad y los inevitables malentendidos. Un "nacionalismo" sin actitudes políticas y culturales excluyentes de los otros, sin proyectos hegemónicos, sería difícil de realizar sin destruir la condición del nacionalismo hegemónico: el Estadonación moderno. El término "nacionalismo" fue acuñado para referirse a la ideología que fundamenta el Estado-nación; no existía antes de esa entidad política. Está ligado, desde sus inicios, a la política opresora o hegemónica que ejerce una nación sobre otras, en el interior de un Estado homogéneo, o a la actitud opresora de un Estado-nación soberano contra otros. Si queremos acabar con el nacionalismo hegemónico, tenemos que cercenar su raíz: el Estado-nación homogéneo. Esto nos lleva a la propuesta de una concepción nueva del Estado: el "Estado plural".

6. Una de las manifestaciones de un Estado plural sería el llamado Estado multicultural. Moulines lo rechaza. Y tiene razón si entiende por él un sistema político en que una etnia (o un "pueblo", en mi terminología) ejerce una hegemonía sobre los demás. El mal está efectivamente en la hegemonía, no en la pluralidad de culturas unidas en un mismo sistema político. Pero todos los que sostenemos la necesidad de pasar de un Estado homogéneo a un Estado plural, entendemos por él justamente lo contrario: sería un Estado resultante de la libre decisión y del acuerdo concertado entre todos los pueblos que lo componen; condición de ese acuerdo sería el trato igual a todos los pactantes. Está claro que esas condiciones no se dan cabalmente de hecho, pero son el objetivo de lucha para la constitución de un Estado multicultural. El Estado plural es, pues, el exactamente contrario al Estado homogéneo producto de la imposición de un pueblo o nación sobre otros. Supone la ruptura de la concepción del Estado-nación que da lugar a todo nacionalismo agresivo.

7. iBien por el principio VIPS (valor intrínseco de la pluralidad del ser)! Es aceptable por razones estéticas y tal vez religiosas. Pero seamos razonables: no puede ser un principio universal de la razón práctica susceptible de dar un fundamento racional a la diversidad cultural. Ha habido sistemas filosóficos incluso que han sostenido el principio contrario: los neoplatónicos en Occidente y el Advaita-Vedanta en Oriente pensaban que el valor supremo era la manifestación de la unidad en el todo, cuya diversidad sería insustancial e ilusoria. Mi simpatía por el VIPS no me impide pensar que para justificar la diversidad cultural debemos acudir a otro camino. Uno posible sería: la libertad de una persona sólo puede realizarse con la condición de la sobrevivencia de la cultura a la que pertenece; luego, la diversidad cultural es una condición de la diversidad de elecciones de vida (o de "formas 
de vida", a lo Wittgenstein) que es constitutiva de la libertad. Éste es un razonamiento ético, no metafísico.

Discrepancias con las posiciones de Moulines las hay; pero muchas de ellas son de nomine y mayores son las coincidencias. Quiero pensar que algo importante nos une: la conciencia de la necesidad de contribuir a erradicar la raíz de los muchos males que asolaron al siglo xx: la persistencia de los Estados nacionales y sus políticas hegemónicas.

Recibido el 27 de junio de 2001; aceptado el 19 de septiembre de 2001 